\title{
Gestão em saúde e as implicaçóes do secretário municipal de saúde no SUS: uma abordagem a partir da análise institucional
}

\author{
I ${ }^{1}$ Lia Bissoli Malaman, ${ }^{2}$ Solange L’Abbate, ${ }^{3}$ Carla Aparecida Spagnol, ${ }^{4}$ Daniel \\ Vannucci Dobies I
}

Resumo: O Sistema Único de Saúde (SUS) define a saúde como direito de todos e dever do Estado. As ações do SUS nos municípios são implementadas pelo secretário de saúde a fim de articular, negociar, acompanhar, avaliar e auditar os serviços e equipes de saúde sob sua responsabilidade. As pressóes inerentes ao cargo somadas às reivindicaçôes da população, do executivo, do legislativo e trabalhadores podem causar sofrimento ou mesmo levar ao adoecimento. Diante desse tensionamento de forças que atravessam a gestão em saúde, elaborou-se esse ensaio teórico com o objetivo de proporcionar reflexões acerca da importância de se analisar o conceito de implicação, considerando a correlação de forças políticas e técnicas desenvolvidas no cotidiano do trabalho dos secretários de saúde e o sofrimento que essa situação pode causar, sobretudo quando a implicação se transforma em sobreimplicação. Para tanto, utilizamos o referencial teóricometodológico da Análise Institucional, com ênfase no conceito de implicaçáo que se refere ao nosso envolvimento de ordem afetiva, ideológica e profissional, sempre presente, até de natureza inconsciente, com tudo o que fazemos. A ausência da análise das implicações, ou a alienação no trabalho, podem impactar na implementação das políticas de saúde, o que reforça a relevância deste estudo.

> Palavras-chave: Saúde Pública, Gestão em Saúde, Análise Institucional.

\author{
${ }^{1}$ Universidade de Campinas. \\ Campinas-SP, Brasil (liabissoli@ \\ yahoo.com.br) \\ ORCID: 0000-0001-5460-2152 \\ ${ }^{2}$ Universidade de Campinas. \\ Campinas-SP, Brasil (slabbate@ \\ lexxa.com.br). \\ ORCID: 0000-0003-2163-0901 \\ ${ }^{3}$ Universidade Federal de Minas \\ Gerais. Belo Horizonte-MG, Brasil \\ (carlaapspagnol@gmail.com). \\ ORCID: 0000-0003-1588-2109 \\ ${ }^{4}$ Universidade de Campinas. \\ Campinas-SP, Brasil (dvdob@ \\ yahoo.com.br). \\ ORCID: 0000-0001-5583-1109
}

Recebido em: 16/12/2019 Aprovado em: 09/06/2020 Revisado em: 17/10/2021 


\section{Introdução}

Instituído pela Constituição Federal de 1988 e fruto do movimento instituinte da Reforma Sanitária, o Sistema Único de Saúde (SUS) foi regulamentado em 1990 e define a saúde como direito de todo cidadão e dever do Estado. A fim de operacionalizar a política pública, foram definidas atribuições dos trabalhadores, gestores, prestadores de serviços e membros dos conselhos deliberativos, visando sua efetivação. Para tanto, no SUS há três níveis de gestão: federal, estadual e municipal, sendo eles regidos por legislaçóes e portarias específicas que determinam as tomadas de decisão de cada ente federativo e a implementação de açôes em cada território. O quadro sanitário e a diversidade dos contextos dos municípios, regiôes e estados brasileiros conferem à gestáo do SUS uma notável complexidade, bastante desafiadora para aqueles que dela se ocupam, imbuídos da tarefa de construir uma sociedade mais justa e igualitária (BRASIL, 2006).

No caso brasileiro, o pacto federativo estabelece equivalência e interdependência de margens de autonomia política dos poderes atribuídos às três esferas governamentais, o que implica na configuração de espaços, processos e práticas de negociação, bem como pactuaçóes de natureza predominantemente política. "Como em quaisquer relaçôes intergovernamentais, há um complexo interativo com competição e cooperação, constrangido pela norma e mediado permanentemente pela política" (BRASIL 2006 p. 12).

Dessa forma, operar o campo da gestão no SUS é sempre bastante desafiador, com setores distintos, pessoas distintas e uma gama enorme de serviços que abrangem diferentes saberes e práticas. Nesse universo, quando se trata do município, há um secretário municipal de saúde ${ }^{1}$ nomeado e com tempo de gestão politicamente delimitado pela duração do mandato do prefeito, podendo ser abreviada, a depender das conjunturas e decisões do executivo municipal. Para tanto, há um projeto político a ser colocado em prática (RODRIGUES e FLEURY, 2015; CAMPOS, 2017).

Em um regime democrático, o prefeito é legitimamente eleito, a partir, em geral, da apresentação de um plano de governo apresentado à população. $\mathrm{Na}$ saúde, a população espera e confia que seu eleito cumpra as promessas de campanha. Para tanto, o prefeito deverá escolher um secretário de saúde que coloque em prática as melhorias prometidas durante a campanha eleitoral, respeitando os preceitos legais. $\mathrm{O}$ trabalho do prefeito é normatizado por legislaçóes que exigem percentuais 
de investimentos nas áreas de maior relevância e em cumprimento das diretrizes federais que norteiam as diferentes realizaçóes propostas.

O prefeito é quem escolhe e nomeia, como "cargo de confiança", o secretário municipal de saúde, denominado gestor do SUS. Esse processo de escolha é, muitas vezes, bastante subjetivo e os critérios não são claros, pois esse gestor pode ser da área da saúde, ou não, podem ter ou não vivência prévia com a estruturação da rede SUS.

Neste contexto, entende-se que:

as prerrogativas de poder e autonomia institucionais desses gestores de saúde, seu capital político, provêm de uma delegação indireta e de uma relação contratual (informal) de confiança para com aqueles gestores públicos que detêm a autoridade política formal de um mandato eletivo. Portanto, o seu arbítrio é sancionado por quem lhes delega o poder de decisão e delimita as suas margens de autonomia política (BRASIL, 2006, p13).

Dessa forma, o gestor municipal de saúde, éo indivíduo com atribuiçôes conferidas por lei, para implementar as ações do SUS no território sob sua gestáo, aplicar os recursos financeiros de acordo com as características sociais, de desenvolvimento e de perfil de morbimortalidade da regiáo. Além disso, esse gestor deve articular, negociar, acompanhar, avaliar e auditar os serviços e equipes de saúde sob sua responsabilidade. Todas essas ações decisórias são articuladas e deliberadas em conjunto com o controle social, através dos conselhos e principalmente das Conferências Municipais de Saúde que, com caráter deliberativo, participam do planejamento, avaliação e aprovação da programação de açôes de saúde e dos indicadores demonstrados e alcançados. Mas, sabemos que isto nem sempre acontece.

Por intermédio dos Conselhos Municipais de Saúde, de acordo com a Constituição de 1988 e as Leis 8080 e 8142 de 1990 (BRASIL 1990), foi instituída a participação popular, mediante composição paritária, de representantes dos usuários, dos trabalhadores e dos prestadores de serviços. Esse órgão colegiado, em tese, deve atuar em conjunto com o gestor na formulação de ações e planejamentos de saúde, tornando a gestão mais participativa e menos verticalizada. Além disso, há outros mecanismos de cogestão e controle, como o Relatório Anual de Gestão (RAG), elaborado mediante a avaliação do Plano Anual de Saúde (PAS).

O RAG é o principal instrumento de comprovação da aplicação dos recursos e tem a finalidade de apresentar os resultados alcançados com a execução da Programação Anual de Saúde e orientar a elaboração da nova programação anual, bem como 
eventuais redirecionamentos que se fizerem necessários no PAS. Embora elaborados e apresentados à comunidade pelo secretário de saúde, em audiências públicas e reuniōes do Conselho Municipal de Saúde, cabe a esse conselho a sua aprovação. É a principal ferramenta de acompanhamento da gestão de saúde no Município, Estado, Distrito Federal e União.

Ainda que o trabalho do gestor não seja isolado, nem a tomada de decisões deva ser feita de forma verticalizada, há uma enorme responsabilidade na implementação das açóes de saúde e mais enfaticamente no gerenciamento do orçamento da saúde, atribuições que cabem ao secretário municipal de saúde.

Nesta perspectiva, este gestor se depara com inúmeras normativas: monitoramento e avaliação das açôes de saúde, responsabilidade fiscal na gestão pública, licitaçôes e contratos administrativos, instrumentos de gestão do SUS (Plano de Saúde, Programação Anual de Saúde, Relatório Anual de Gestão), Sistemas de Informação em Saúde como ferramenta de planejamento, bem como, a elaboração de diretrizes objetivos e metas em saúde (CONASEMS, 2016).

Mas, nem sempre os planos da administração política e do chefe do executivo municipal são passíveis de implementação. A lógica das Regiôes de Redes de Atenção à Saúde (RRAS) delimita os territórios geograficamente, que podem ou não conter determinados equipamentos de saúde. Todas as ações são pactuadas nas Comissões Intergestoras Regionais (CIRs), que também possuem um caráter políticoadministrativo naquela região de saúde, que devem planejar as açóes regionalmente, de acordo com o perfil de adoecimento da população. Posteriormente, as Comissóes Intergestoras Bipartites (CIB) e as Comissôes Intergestoras Tripartites (CIT) irão aprovar ou não as decisóes tomadas regionalmente.

Sendo assim, o SUS é ou deveria ser uma política de Estado e não de governo, pois, segundo Vasconcelos e Pasche (2006), esse sistema configura-se como um arranjo organizacional do Estado brasileiro que dá sustentação às políticas de saúde no país, traduzindo em ações os princípios e diretrizes destas políticas. Dessa forma, o SUS deve ou deveria se constituir para além das forças político-partidárias, de comando dos governos locais, consolidando-se como uma política instituída nacionalmente. Caso contrário, sua defesa e força de efetivação se fragilizam e colocam as políticas de saúde apenas no campo das negociaçôes partidárias, o que pode interferir principalmente nos recursos financeiros destinados à saúde da população. 
De acordo com Campos (2000, p. 85):

os atores envolvidos na pactuação dos critérios e mecanismos de financiamento do SUS se articulam em uma rede cuja estrutura se conforma de maneira bastante heterogênea e complexa. Observa-se grande diversidade na estruturação e funcionamento dessa rede, no nível dos estados e regiōes, o que permite considerar a existência, não de uma única rede, mas de diversas 'subredes' (ou de componentes menores de uma única rede) que articulam atores situados em diferentes níveis do sistema de saúde, interligadas de forma mais ou menos consistente.

Embora o SUS seja o maior sistema de saúde universal, público e gratuito do mundo, ainda é frágil sua efetivação e, atualmente, passa por uma profunda crise, com sérios riscos de perda daquilo que já foi conquistado pela sociedade e consolidado por esse sistema, que é destinado a milhōes de brasileiros (CAMPOS, 2015). Um dos fatores desta crise é o seu subfinanciamento, reforçado pela aprovação da PEC 95- Emenda Constitucional 95/2016-, que limita por 20 anos os gastos públicos, propôe modelos de gestâo por Organizaçôes Sociais de Saúde (OSS), incentiva a privatização dos setores prestadores de serviços de saúde, colocando em risco a manutenção do SUS, universal, equânime e integral e "dá ares de empreendedorismo ao setor saúde" (NARVAI, 2018 p. 1).

A defesa do SUS passa pela luta contra a desigualdade, pela alteração da política econômica e social vigente, impondo intervençôes públicas voltadas para a promoção da igualdade e do bem-estar. Nessa direção, Campos (2018, p. 01) afirma que:

a "esperança somos nós... e os outros" é uma metáfora para expressar a certeza de que a defesa do SUS, da democracia e dos direitos sociais, nesse momento em particular, depende da sociedade civil mais do que do Estado e dos políticos profissionais. Depende da revitalização do movimento sanitário e de sua articulação com amplos setores da sociedade - movimentos de luta por direitos, como o das mulheres, dos idosos, das populaçóes indígenas e negra, dos portadores de patologias, das várias crenças religiosas que participam também da vida social, dos sindicatos, enfim, temos que verbalizar um projeto inclusivo de sociedade e, especificamente, de direito à saúde.

A pressão popular associada às demandas dos chefes do executivo e legislativo em área tão sensível como a saúde exige do exercício da gestão um constante equilíbrio e flexibilização para a efetiva realização das açôes de saúde necessárias às demandas da população. A pressão do chefe do executivo sobre o secretário de saúde é ainda acirrada pelas demandas econômicas dos municípios e o crescente subfinanciamento da saúde, que obriga o gestor a cumprir as diretrizes em saúde para além do orçamento planejado. 
Segundo Santos (2012, p. 274):

a gestâo descentralizada do SUS, especialmente as secretarias municipais de saúde, permanecem tensionadas e angustiadas quando, por um lado, por princípio humano e para evitar omissão de socorro, concentram os baixos recursos nas situações de urgência e as mais graves, com serviços supercongestionados, frequentemente acrescentando recursos municipais aos valores da tabela federal.

Em meio a todas essas decisóes, propostas e mudanças de modelos de financiamento por parte do governo federal, há um secretário de saúde que deve planejar e implantar nos municípios as açôes de saúde e consolidar o SUS, enquanto modelo de atenção à saúde. Isso pode acontecer com maior ou menor resistência, dependendo do grau de vinculação e das implicaçôes dos secretários de saúde com a implementação do SUS nos seus municípios.

Mas há uma enorme diferença entre cumprir a normatização, investir no que a legislação determina e defender um sistema público, universal, equânime e integral de saúde, dentro da sua complexidade. Não existe defesa do SUS sem reflexão crítica sobre o que é o SUS, suas peculiaridades, desafios e caminhos.

Além disso, não há curso direcionado à formação ou habilitação de profissionais que prepare para o cargo de secretário municipal de saúde, é um aprendizado "em ato". O secretário de saúde carrega consigo a sua implicação, fortemente determinada pela sua formação de origem. Enfermeiros, médicos, demais profissionais da saúde que ocupam os cargos de gestão, ou ainda profissionais sem formação nenhuma em saúde, têm modos de agir em gestão que diferem uns dos outros. Portanto, analisar a implicação profissional é analisar a relação que os sujeitos estabelecem com a sua profissão (identificada como uma instituição) e com as demais instituiçôes que de algum modo se relacionam com sua prática (BORGES et al, 2019 p. 03).

Nessa perspectiva, analisar a implicação profissional é analisar também a relação que "o sujeito estabelece com a profissão (pensada como instituição com sua dinâmica própria) a qual ele pertence, e com as outras instituições nas quais, ou em ligação às quais, ele exerce sua profissão" (MONCEAU, 2015, p. 198).

Sendo assim, o objetivo deste artigo é proporcionar reflexóes acerca da importância de se analisar as implicaçóes relacionadas às práticas profissionais inerentes ao cargo de Secretário Municipal de Saúde do SUS e o possível sofrimento que esse tipo de situação pode causar, sobretudo quando a implicação se transforma em sobreimplicação. 
Os conceitos de implicação e sobreimplicação foram elaborados por autores institucionalistas, a partir do referencial teórico metodológico da Análise Institucional que será abordado no próximo tópico.

\section{Referencial teórico-metodológico da análise institucional}

Os principais teóricos que fundaram e sistematizaram o referencial teóricometodológico da Análise Institucional (AI) nos anos de 1960, na França, foram René Lourau em parceria com Georges Lapassade. A AI aportou no Brasil na década de 1970, no âmbito de organizaçôes acadêmicas e sociais (L'ABBATE, 2018; 2019).

Um dos conceitos centrais da AI é o de instituição elaborado por Lourau (2014) como uma norma universal, ou considerada como tal, quer se trate do casamento ou da educação, quer da medicina, do trabalho assalariado, do lucro, do crédito.

Para este autor, toda instituiçáo passa, de forma constante por processos de mudança e acomodaçóes, muitas vezes tensas, dependendo das ações dos sujeitos que a compóem e do contexto social mais amplo no qual se insere. Diante disso, podemos considerar a gestão como uma instituição e o profissional gestor como alguém que, mesmo seguindo o que é determinado para o exercício da sua função, poderá deixar sua marca pessoal no período no qual trabalhou, ao propor novos aportes e mudanças. Isto irá depender, em grande parte, da implicação do gestor com os processos de gestão, com as instituições que atravessam sua prática profissional, bem como com o contexto mais amplo da sociedade na qual tais instituiçóes se inserem.

Neste sentido, outro conceito central para a AI é o de implicação, que se refere ao nosso envolvimento de ordem afetiva, ideológica e profissional, sempre presente, até de natureza inconsciente com tudo o que fazemos (BARBIER, 1985; LOURAU, 2004 a). Segundo este conceito, tanto os que estão engajados como os não engajados nas atividades de uma determinada instituição encontram-se, de alguma forma, implicados com a instituição da qual fazem parte (LOURAU, 2007).

Para Monceau (2008) o que se entende por implicação é a relação que os indivíduos desenvolvem com as instituiçōes. Pode-se dizer que o indivíduo é tomado pela instituição, querendo ele ou não.

As implicações deveriam ser sempre analisadas coletivamente pelos sujeitos, mas há pontos de cegueira, que Lourau (2004b) denominou de sobreimplicação, que ocorre quando o sujeito reproduz tão automática e intensamente as normas institucionais, que perde a capacidade de analisar as suas açóes. Ao propor o 
conceito de sobreimplicação, Lourau (2004 b, p. 195) afirma que ela "não só produz sobretrabalho, estresse rentável, doença, morte e mais-valia, como também cashflow, benefício absolutamente nítido consagrado ao reinvestimento e, portanto, ao crescimento indefinido da empresa-instituição".

No caso do gestor municipal de saúde, a quantidade e complexidade dos vértices que atuam no campo de forças, no qual está inserido, conforme descrito na introdução e ilustrado na Figura 1, podem levar o gestor a uma prática fortemente comprometida pelo cumprimento de normas e tarefas, sem levar em conta os atravessamentos institucionais da conjuntura social e política. Neste sentido deve-se destacar também o papel do Estado, que, para a Análise Institucional, configura-se como um conjunto de instituiçóes, dentre as quais, portanto, o próprio SUS. Neste sentido, Lourau (1978) argumenta que o Estado atua, até de forma inconsciente, sobre o conjunto da sociedade e das instituiçóes.

É importante assinalar também que pode acontecer da implicação transformar-se em sobreimplicação e esta, muitas vezes, poderá resultar em malestar e até em adoecimento.

Sobreimplicados, os sujeitos perdem a dimensão institucional das suas açôes, incidindo em naturalizações e responsabilizações individuais em fenômenos que são produzidos socialmente e que estão presentes constantemente na prática profissional.

No âmbito da AI, também são importantes os conceitos de transversalidade e analisador (GUATTARI, 1987). Transversalidade diz respeito aos diferentes vínculos que atravessam nossas atividades, e em relação aos quais podemos atuar de forma autônoma como sujeitos ou heterônoma como sujeitados. Analisador é o que permite "revelar a estrutura da organização provocá-la, forçá-la a falar" (Lourau, 2014, p. 303), ou seja, é preciso estar atento a fatos e situaçóes que embora pareçam sem muita relevância, podem ocultar aspectos que o gestor deve dar atenção. (parágrafos unidos) É mediante a análise das implicaçôes que os sujeitos poderão localizar os analisadores e os vínculos relacionados à transversalidade nos processos de gestão.

\section{A análise das implicaçóes e a prática profissional do secretário municipal de saúde}

A Figura 1 foi construída com a finalidade de mostrar a composição das forças e tensionamentos que atuam no campo da gestão em saúde, o que remete à discussão 
sobre a saúde para além do universo territorial onde se insere o secretário municipal de saúde. Nesse contexto, os atravessamentos políticos são bastante presentes. Emendas parlamentares e demandas político-partidárias aparecem como determinantes na negociação para implementação de equipamentos de saúde que nem sempre estão inseridos na lógica da construção das Redes de Saúde (CONASEMS, 2016).

Figura 1. Os atravessamentos e sobreposições na prática do gestor de saúde.

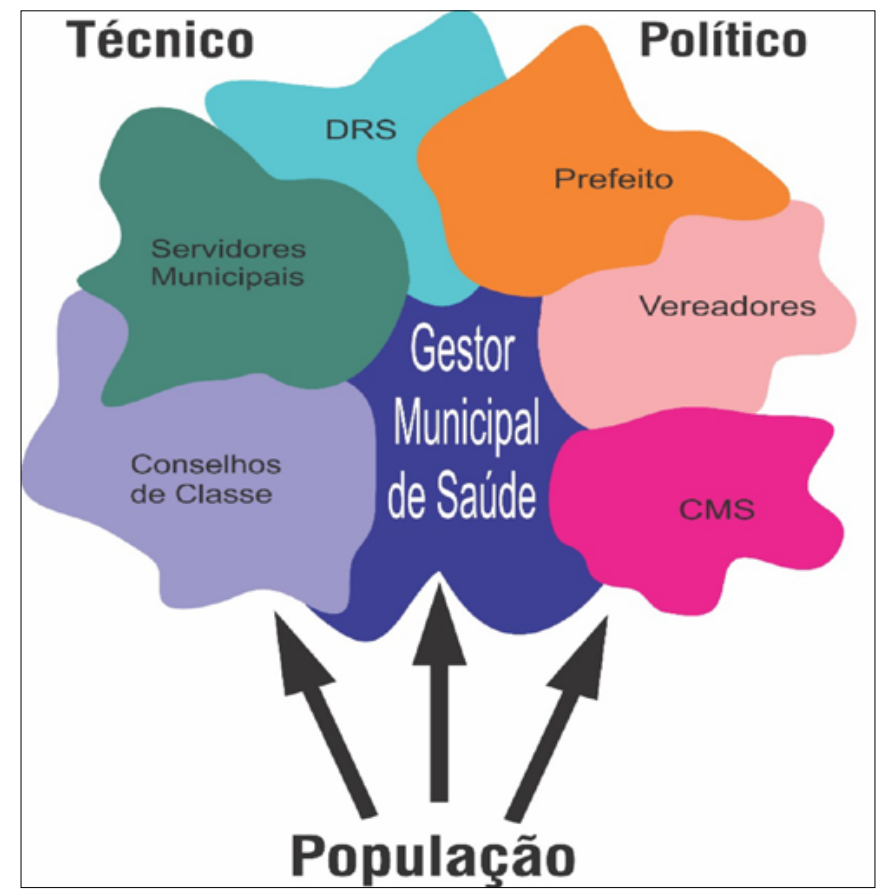

Fonte: elaborado pelos autores.

Ao ilustrar o campo de forças no qual o secretário municipal de saúde está inserido, esta figura permite visualizar os principais atravessamentos com os quais ele deverá lidar para executar a política de saúde com a qual se comprometeu. Para tanto, é necessário que este gestor compreenda o sentido e significado da sua prática profissional e analise suas implicaçóes com o SUS e com o projeto político do prefeito que o nomeou, bem como toda a pressão dos diversos atores técnico-políticos, dentre os quais a população, que por vezes emerge suas reivindicaçôes diretamente, sem submeter-se às instâncias hierárquicas de representação, que muitas vezes as soterram. 
Só assim, o secretário poderá entender como ocorrem essas correlaçôes de forças e se elas interferem ou não na defesa e efetivação do SUS no território sob sua gestão.

De forma ampla, pode-se afirmar que a prática profissional se refere a toda prática social, que inclui as maneiras de se relacionar com os membros de uma profissão e, no caso do campo da saúde, com as outras profissóes deste campo, de refletir sobre essas relaçôes e lhes atribuir valores e sentidos. Sendo assim, a prática profissional "é constituída do conjunto de atualizaçôes das implicaçóes profissionais de um sujeito, principalmente das falas, das escritas e dos atos" (MONCEAU, 2015, p. 198).

Ainda segundo Monceau (2008), querendo ou não, os indivíduos são tomados pelas instituições, e, por isso, não se pode confundir o conceito de implicação com engajamento ou investimento. Para o autor a implicação é a relação que os indivíduos desenvolvem com as instituiçôes. Lourau (2007, p.14) alerta que é muito dolorosa a análise das nossas implicaçóes, dos lugares que ocupamos ativamente nesse mundo e faz uma provocação: "amamos nossa alienação".

A ideia de alienação, segundo Marx ocorre quando o trabalhador não se identifica, ou não se reconhece naquilo que produziu. $O$ trabalho deixa de ser a "satisfação de uma necessidade, mas apenas um meio para satisfazer necessidades externas a ele" (MARX, 1994, p. 202). A alienação ativa ou atividade de alienação mostra o trabalho como sofrimento e não realização. $\mathrm{O}$ trabalho não é uma feliz confirmação de si e desenvolvimento de uma livre energia física e espiritual, mas antes sacrifício de si e mortificação. A consequência é uma profunda degeneração dos modos do comportamento.

É possível associar a alienação à noção de desimplicação que, para Lourau (1997), é a situação que ocorre quando o sujeito não percebe nenhum tipo de compromisso com as atividades pelas quais deveria se responsabilizar e consequentemente com a instituição na qual exerce seu trabalho. Mas este desconhecimento pode também trazer sofrimento e até adoecimento, porque mesmo "percebendo-me irresponsável", sou responsável pelo que faço, sou cobrado pelo que não faço (Lourau, 2007, p. 15).

Inicialmente, os estudos relacionando trabalho e adoecimento se referiram ao trabalho braçal, sobretudo quando era exigido do trabalhador máxima produtividade, podendo inclusive produzir morte por excesso de trabalho, fenômeno que no Japão é denominado karoshi (LOURAU 2004b).

Sem dúvida, a organização do trabalho pode exercer sobre o homem uma ação específica, cujo impacto é o aparelho psíquico. Neste sentido, Dejours 
(1992) chama a atenção para diferentes mecanismos de defesa utilizados pelos trabalhadores. Esses mecanismos permitem sobreviver ao sofrimento imposto pela organização do trabalho vigente.

Em tempos mais recentes, pesquisadores interessados no estudo das condiçóes de trabalho de ordem intelectual, administrativa e de gerência, começaram a se perguntar se este tipo de trabalho também poderia provocar mal-estar, desgaste e até adoecimento. Um desses estudiosos, Vincent de Gaulejac, que inicialmente se preocupou em estudar estas questôes com relação ao trabalho realizado na empresa privada, percebeu que o fenômeno também ocorria com trabalhadores que exerciam trabalho de gestão em organizaçóes públicas (GAULEJAC, 2007; 2012).

Como exemplo, este autor transcreveu a carta da diretora de um Departamento de Proteção Judiciária em Paris, que não suportando mais a contradição entre as funções para as quais ela havia sido contratada e com as quais se identificava, com as que ela era obrigada a realizar, com as quais não se identificava, resolveu se suicidar, atirando-se da janela do terceiro andar onde estava seu escritório. Tratase na verdade das contradiçôes entre as lógicas organizacionais e as finalidades institucionais, ou seja, entre as concepçôes que fundamentam a nova gestáo pública e as missões do serviço público confiadas a estas instituiçôes (GAULEJAC, 2012) (Tradução dos autores).

Uma pesquisa qualitativa realizada em 2019, inicialmente com oitenta 80 indivíduos que estavam em situaçôes diversas no mercado de trabalho, tais como: servidores públicos, profissionais liberais, trabalhadores da indústria e do setor de serviços, em cargos de liderança, desempregados, afastados por doenças psíquicas, entre outras, buscou compreender como se estabelece o sofrimento psíquico oriundo do trabalho (ou da sua ausência) nos tempos atuais (CAPELLANO e CARRAMENHA, 2019).

Os autores, ao analisar os cargos de gestão ou direção de empresas observaram que o sofrimento parece estar ligado à obrigação dos profissionais de sustentar uma imagem de vitória e sucesso apesar das adversidades que encontravam no dia a dia. Não se pode esmorecer ou demonstrar sofrimento, pois isto seria uma derrota e uma perda do status conquistado. Assim, os profissionais sentem-se constantemente coagidos a mostrar que têm poderes para resolver problemas e ajudar quem precisa (CAPELLANO e CARRAMENHA, 2019).

Para os altos executivos, é preciso se mostrar sempre como um guardião da moral e um exemplo do êxito, mesmo em situaçôes desfavoráveis. Nesses casos, 
para minimizar o sofrimento, estes profissionais adotam uma estratégia defensiva que é quase uma sabotagem de si, uma autoanulação: abstenção de se posicionar, passando a trabalhar no automático para entregar aquilo que lhes é pedido sem questionamentos (CAPELLANO e CARRAMENHA, 2019).

No caso do gestor municipal de saúde, é preciso considerar também as pressôes de ordem política que certamente sofre na sua relação com os diversos profissionais e instituiçôes com as quais obrigatoriamente se relaciona e que atravessam a sua prática profissional, tais como: o prefeito, os vereadores da Câmara Municipal, os deputados da região e até o Conselho Municipal de Saúde, cujos membros podem não estar totalmente afinados com o SUS como instituição, em conformidade com que está determinado pela Constituição Federal de 1988.

Portanto, entende-se que na busca pela implementação efetiva do SUS, quanto mais o gestor municipal de saúde estiver implicado positivamente com a gestão, responsabilizando-se em conjunto com outros atores políticos com sua organização, que muitas vezes vem acompanhada de dificuldades tais como: diminuição de recursos, contingenciamentos, cortes no orçamento municipal de saúde, questóes salariais dos trabalhadores, admissão e demissão de funcionários, dimensões que afetam a qualidade do serviço ofertado à população, maior será seu estado de tensão, de angústia e sofrimento que poderá se transformar em adoecimento.

Neste sentido, a análise das implicaçôes, que é realizada de forma coletiva, pode contribuir para se compreender melhor a gestáo colegiada no SUS, dando visibilidade aos tensionamentos que ocorrem entre as reais necessidades de saúde da população e a militância, os interesses políticos e econômicos, as realidades locais, entre outros fatores que interferem diretamente na prática profissional do gestor municipal em saúde. Isso pode, em certa medida, reduzir o sofrimento e a angústia provocados em algumas situações pela sobreimplicação dos atores envolvidos na gestão, destacando aqui o gestor municipal de saúde.

Com a relevância do tema, têm surgido pesquisas que mostram a importância de se analisar as implicaçóes nos processos de gestáo dos SUS, destacamos aqui a pesquisa com apoio matricial, como em PENIDO 2015, ou entre os apoiadores de humanização e articuladores como em BORGES, 2019.

Os referidos estudos e outros reforçam a relevância desse ensaio teórico que se propôs a realizar uma reflexão acerca da importância de se analisar coletivamente as implicaçôes na prática profissional dos secretários municipais de saúde, para que 
não sejam tomados por sobreimplicaçôes, perdendo assim a capacidade de análise dos diversos fatores que atravessam a gestão do SUS.

\section{Considerações finais}

O cargo de Secretário Municipal de Saúde no SUS carrega em si inúmeros atravessamentos e responsabilidades, uma vez que se situa entre os campos político e técnico da saúde, ou melhor, num campo técnico-político, a considerar a intersecção entre eles. As pressóes inerentes ao cargo com as reivindicações da população, do chefe do executivo, do corpo legislativo através dos vereadores, deputados, entidades de classe, conselhos profissionais, segmento dos trabalhadores e das legislaçóes regulamentadoras do SUS, causam sofrimento e podem levar ao adoecimento se não houver a análise das implicaçôes do gestor com as práticas profissionais por ele desenvolvidas no cotidiano da gestão.

Sendo assim, é de grande relevância outros estudos teóricos e pesquisas de campo que aprofundem as reflexóes acerca da necessidade da análise das implicações, uma vez que a ausência das mesmas, com uma alienaçáo no trabalho, pode impactar inclusive na implementação das políticas de saúde naquele território.

Para concluir, esperamos que este estudo teórico possa balizar pesquisas no campo da gestão em saúde e do papel do secretário municipal de saúde na implementação e fortalecimento das políticas de saúde e do próprio SUS, que possam apresentar arranjos e possibilidades de modos singulares e inventivos de exercer a gestão em saúde.

\section{Referências}

BARBIER, R. O Conceito de "Implicação" na Pesquisa-Açáo em Ciências Humanas. In: Pesquisa-Ação na instituição educativa. Rio de Janeiro, Editora Zahar, 1985.PERDA

BORGES F.A., FORTUNA C.M., FELICIANO A.B., OGATA M.N., KASPER M., SILVA M.V. A análise de implicação profissional como um dispositivo de educação permanente em saúde Rev. Latino-Am. Enfermagem. 2019; 27:e3189. [Access 23-10-2019] http://www.scielo.br/ pdf/rlae/v27/pt_0104-1169-rlae-27-e3189.pdf;

BRASIL Lei No. 8080/90, de 19 de setembro de 1990. Brasília: DF. 1990. Disponível em https:// www.planalto.gov.br/ccivil_03/LEIS/L8080.htm Acesso em: 15 set. 2019.

BRASIL Lei No. 8142/90, de 28 de dezembro de 1990. Brasília: DF. 1990. Disponível em http:// www.planalto.gov.br/ccivil_03/Leis/L8142.htm Acesso em: 15 set. 2006. 
BRASIL, Ministério da Saúde. Secretaria-Executiva. Departamento de Apoio à Descentralização. Gestores do SUS: olhares e vivências / Ministério da Saúde, Secretaria-Executiva, Departamento de Apoio à Descentralização. - Brasília : Editora do Ministério da Saúde, 2006. 193 p.

BRASIL. Constituição da Republica Federativa do Brasil de 1988, Título VIII da Ordem Social, Capítulo II, Seção II, Artigo 200-III. Senado, Brasília: DF. 1988. Disponível em https://www. planalto.gov.br/ccivil_03/LEIS/L8080.htm Acesso em: 05 set. 2019.

CAMPOS, G. W. S. A defesa do SUS depende do avanço da reforma sanitária. Interface (Botucatu), Botucatu, v. 22, n. 64, p. 5-8, mar. 2018 . Acessos em 10 set. 2019. http://dx.doi. org/10.1590/1807-57622017.0772.

CAMPOS, G. W. S. et al. Entrevista com o Professor Gastão Wagner de Sousa Campos. Saúde debate, Rio de Janeiro, v. 39, n. spe, p. 338-339, 2015

CAPPELLANO, T.; CARRAMENHA, B. Trabalho e sofrimento psíquico: Histórias que contam essa História. São Paulo: Atarukas Produção Editorial, 2019167 p

CONASEMS-Manualdo (a) Gestor (a) Municipaldo SUS: "Diálogos no Cotidiano"/CONASEMS COSEMS/RJ, LAPPIS/IMS/UERJ- Rio de Janeiro: CEPESC/IMS/UERJ,2016 324 p

DEJOURS, C. A loucura do trabalho: estudo de Psicopatologia do Trabalho. Christophe Dejours; tradução Ana Isabel Paraguay e Lucia Leal Ferreira - 5a ed. Ampliada São Paulo: Cortez -Oboré, 1992.

GAUlEJAC, V. Gestão como Doença Social. $3^{\mathrm{a}}$ ed. Aparecida/SP Ideias e Letras, 2007.

GAULEJAC, V. La recherche malade du management. Versailles, Éditions Quae, 2012.

GUATTARI, F. A transversalidade. In: Revolução Molecular: pulsaçôes políticas do

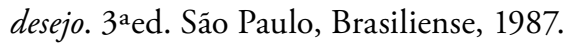

L'ABBATE, S. A trajetória da Saúde Coletiva no Brasil: análise das suas dimensôes políticas e educativas em articulação com a Análise Institucional - Mnemosine Vol.14, no2, p. 236-262 (2018) - Biografia. Disponível em https://www.e-publicacoes.uerj.br/index.php/mnemosine/ article/view/41691/pdf_386 Acessado em outubro de 2019

L'ABBATE, S. Análise Institucional e Saúde Coletiva: pesquisa e intervenção. In: DOMINGUES, A.R.; L'ABBATE, S.; RUSCHE, R.J. (Orgs) Análise Institucional: perspectivas contemporâneas, teorias e experiências. São Paulo, Hucitec, 2019, p. 75-94.

L'ABBATE, S. A análise institucional e a saúde coletiva. Ciênc. saúde coletiva, Rio de Janeiro , v. 8, n. 1, p. 265-274, 2003. Available from http://www.scielo.br/scielo.php?script=sci_ arttext\&pid=S1413- 1232003000100019\&lng=en\&nrm=iso $>$. access on 23 Oct. 2019. http:// dx.doi.org/10.1590/S1413-81232003000100019.

LOURAU, R. L' État-inconscient. Paris, Les Editions de Minuit, 1978. 
LOURAU, R. Implicação e sobreimplicação. In: ALTOÉ, S. (org.) René Lourau. Analista Institucional em Tempo Integral. São Paulo, Hucitec, 2004a, p. 186-198.

LOURAU, R. A Análise Institucional. 3a Ed. Petrópolis, Vozes, 2014.

LOURAU, R. Implicação: um novo paradigma. In: ALTOÉ, S. (org.) René Lourau. Analista Institucional em Tempo Integral. São Paulo, Hucitec, 2004b, p. 246-258.

LOURAU, R. La Clé des Champs. Une introduction à l'analyse institucionnelle. Paris, Anthropos, 1997.

LOURAU, R. René Lourau na UERJ - 1993. Análise Institucional e Práticas de Pesquisa. Rio de Janeiro: Editora da UERJ, 1993. Mnemosine. Vol.3, n², 2007. Disponível em: http://www. mnemosine.cjb.net/mnemo/index.php/mnemo/issue/view/20 Acesso em 22 novembro. 2019.

MARX, K. O Capital: critica da economia politica. 6 vol. Terceiro Manuscrito, 195-202 Rio de Janeiro: Bertrand Brasil, 1994, 6 vols.

MERHY, E. E. O ato de governar as tensôes constitutivas do agir em saúde como desafio permanente de algumas estratégias gerenciais. Ciênc. Saúde coletiva, Rio de Janeiro, v.4; n 2 p.305-314,1999

MONCEAU, G. Implicação, sobreimplicação e implicação profissional. Fractal Revista de Psicologia, v. 20 - n.1, p.19-26. Jan/Jun. 2008.

MONCEAU, G. Técnicas socioclínicas para a análise institucional das práticas sociais. Psicologia em Revista, v. 21, n. 1. Belo Horizonte, 2015.

NARVAI, P.C. Sus, 30 anos de resistência e contra-hegemonia Disponivel em https://www. abrasco.org.br/site/outras-noticias/sistemas-de-saude/sus-30-anos-de-resistencia-e-contrahegemonia/34213/ ABRASCO , 17 de maio de 2018 Acessado em abril de 2019 p.105-123.

PAIM, J. S. A reforma sanitária brasileira e o Sistema Único de Saúde: dialogando com hipóteses concorrentes. Physis [online]. 2008, vol.18, n.4 [acess 2019-08-03], pp.625-644. https://dx.doi. org/10.1590/S0103-73312008000400003

PAIM. J. Reforma Sanitária Brasileira: avanços, limites e perspectivas. In: Matta, G.C. (org.) Estado, sociedade e formação profissional em saúde: contradiçôes e desafios em 20 anos de SUS. I Rio de Janeiro: Editora Fiocruz/ EPSJV, 2008. P. 91-122

PENIDO CMF. A análise da implicação como dispositivo de transformação do processo de trabalho. Gerais, Rev. Interinst. Psicol., Juiz de Fora, v. 8, n. spe, p. 248-257, dez. 2015. Disponível em http://pepsic.bvsalud.org/scielo.php?script=sci_arttext\&pid=S1983$2202015000200007 \& \operatorname{lng}=$ pt\&nrm=iso $>$. acessos em 22 mar. 2020.

RODRIGUES, P. H.A.; FLEURY, S. Uma rica avaliação da construção da gestão democrática da saúde no nível local. Rio de Janeiro: Cebes: Editora Fiocruz, 2014. Saúde debate, v. 39, n. spe, p. 340-344, 
SANTOS, N.R. SUS, política pública de Estado: seu desenvolvimento instituído e instituinte e a busca de saídas. Ciênc. saúde coletiva, Rio de Janeiro, v. 18, n. 1, p. 273-280, Jan. 2013. VASCONCELOS, C. M.; PASCHE, D. F. O Sistema Único de Saúde. In: CAMPOS, G. W. S. et al. (Org.). Tratado de saúde coletiva. São Paulo: Hucitec; Rio de Janeiro: Fiocruz, 2006. p. $531-562$.

\section{Nota}

${ }^{1}$ Vale frisar que existem duas denominaçóes para a gestão de Saúde, o Secretário Municipal de Saúde e o Diretor de Saúde. Embora caiba aos dois a gestão do SUS em seus municípios e as atribuiçóes e responsabilizaçóes sejam as mesmas, não sendo encontradas nas legislações norteadoras da gestão, qualquer diferenciação entre ambos, alguns municípios ainda usam a denominaçâo de Diretor de Saúde. Para os autores, a fim de facilitar a redação, neste artigo, os autores utilizam o termo mais corriqueiro, "secretário municipal de saúde". 


\section{Abstract}

\section{Health management and the implications of the municipal health secretary in sus: an approach from institutional analysis} The Unified Health System (SUS) defines health as the right of every citizen and the duty of the State. SUS actions in the municipalities are implemented by the health secretary in order to articulate, negotiate, monitor, evaluate and audit the health services and teams under his responsibility. The pressure inherent to the position with the demands of the population, the chief executive, the legislative body and the segments of workers can cause suffering or even lead to illness. In view of this tensioning of forces that cross health management, this theoretical essay was developed with the objective of providing reflections on the importance of analyzing the concept of implication, considering the correlation of political and technical forces developed in daily life of the work of the health secretaries and the suffering that this situation can cause, especially when the implication turns into over-implication. For this, we use the theoretical-methodological framework of Institutional Analysis, with emphasis on the concept of implication that refers to our involvement affective, ideological and professional, always present, even unconscious, with everything we do. The absence of an analysis of the implications, or alienation at work, may impact the implementation of health policies, which reinforces the relevance of this type of study.

> Keywords: Public Health, Health Management, Institutional Analysis. 